\title{
GASTROINTESTINAL WATER AND ELECTROLYTES. II. THE EQUILIBRATION \\ OF RADIOPOTASSIUM IN GASTROINTESTINAL CONTENTS AND THE PROPORTION OF EXCHANGEABLE POTASSIUM $\left(\mathrm{K}_{\mathbf{e}}\right)$ IN THE GASTROINTESTINAL TRACT ${ }^{1}$
}

\author{
By J. NADELL, 2 N. J. SWEET, AND I. S. EDELMAN 3
}

\author{
(From the Department of Medicine, University of California School of Medicine, and the San \\ Francisco Hospital, San Francisco, Calif.)
}

(Submitted for publication September 14, 1955 ; accepted December 19, 1955)

Only 1.5 to 2.5 per cent of total body potassium is found in the extracellular fluid as estimated by tracer dilution methods (1-3). The usual methods for estimating extracellular potassium content, however, do not take into account fluid contained in the lumen of the gastrointestinal tract or in other transcellular fluid $(4,5)$.

The concentration of potassium in the secretions of the gastrointestinal tract is equal to or greater than that in plasma. In saliva, the concentration is approximately 4 times that of plasma, in gastric juice 2 to 3 times that of plasma, and in small and large intestinal secretions 1.5 to 2.5 times that of plasma (6-8). Abnormal loss of gastrointestinal fluids is known to produce rapid potassium depletion due to the loss of potassium contained in gastrointestinal secretions, as well as continued renal excretion of potassium $(9,10)$.

Endogenous potassium contained in the gastrointestinal tract is transported, at least in part, from blood to gut by secretory mechanisms. Using tracer techniques Corsa, Olney, Steenburg, Ball, and Moore (1) demonstrated that bile potassium is in equilibrium with the total pool of exchangeable potassium 10 hours after intravenous administration of radiopotassium. Exogenous potassium is rapidly absorbed from the gastrointestinal tract after the oral administration of isotopic potassium to rabbits; equilibrium between the in-

1 This work was carried out under grants from the American Heart Association, the United States Public Health Service (Grant No. H-1441), the Fleischmann Foundation, the San Francisco Heart Association, the Paul and Susan Gardiner Fund, and the Christine Breon Fund assigned by the Medical Research Committee of the University of California School of Medicine, San Francisco.

2 Research Fellow of the National Heart Institute of the United States Public Health Service.

${ }^{8}$ Established Investigator of the American Heart Association. testinal contents and serum is almost complete in one hour (11). In view of these findings, an analysis of the equilibration of isotopic potassium in gut contents and estimation of the amount of potassium in the alimentary tract was considered worthwhile. The known role of gastrointestinal losses in the genesis of potassium depletion is an additional basis for this study.

The first paper in this series (4) reported the results of measurement of intraluminal gastrointestinal sodium content in rabbits and in human subjects studied postmortem. The present study is similar in design and execution to the study on gastrointestinal sodium content and presents observations on a) the amount of intraluminal gastrointestinal potassium relative to total exchangeable potassium $\left(K_{e}\right)$ and the extent of radiopotassium exchange equilibrium in gastrointestinal contents in rabbits and b) the amount of intraluminal gastrointestinal potassium in human subjects studied postmortem.

\section{METHODS}

\section{A. Rabbits}

Forty-four adult albino rabbits were studied in pairs consisting of a male and a non-gravid female. Water was permitted ad libitum from the time of isotope injection until sacrifice, but food was withheld during this period.

Each animal was injected intraperitoneally with 250 to 350 microcuries of $\mathrm{K}^{a / \infty} \mathrm{Cl}$ from calibrated syringes. The solution was made isotonic with $\mathrm{NaCl}$, sterilized, and neutralized to $\mathrm{pH} 7$. No contamination with other isotopes was present.

Urine, stool, gastrointestinal contents and blood were

4 The $K^{a / a}$ mixture was prepared in the Crocker Radiation Laboratory, University of California, Berkeley, by alpha particle bombardment of argon. At the time of radioassay the resultant mixture of $\mathrm{K}^{\text {* }}$ (half-life, 12.4 hours) and $\mathrm{K}^{*}$ (half-life, 22.4 hours) contained approximately 75 per cent $K^{\omega}$ and 25 per cent $K^{\star *}$. $K^{\omega}$ emits 0.81 and $0.24 \mathrm{Mev}$ electrons and $0.4 \mathrm{Mev}$ gamma-transitions. 
collected for assay of radioactivity and chemical analyses as described in the first paper in this series (4). In some instances erythrocytes were aspirated from below the separated plasma of centrifuged heparinized blood. These red cells were then hemolyzed in 3 to 4 times their volume of distilled water. After being filtered through paper, aliquots were taken for assay of radioactivity and chemical analysis.

One-ml. aliquots of plasma, lyzed erythrocytes, bladder urine, gastrointestinal contents and excreted urine were plated in triplicate on filter paper, dried under an infrared lamp and covered with Parafilm. Three separate dilutions of the injected isotope solution were plated in triplicate and processed as above. Radioactive assay in the first 6 rabbits studied was carried out with an aluminum-covered end-window, thallium-activated sodium iodide scintillation counter and autoscaler. Because of the slow counting rates obtained with the scintillation counter, radioassays on samples obtained from the following 38 rabbits were measured with a thin mica endwindow Geiger-Müller tube 5 and autoscaler. Preliminary observations revealed no significant self-absorption loss up to twice the quantity of solids present in the experimental samples. Correction for coincidence loss was unnecessary; with the counting tube used, no significant coincidence loss occurred at counting rates up to 4000 counts per minute. The counting rates did not exceed this value.

All samples were corrected for background radiation and radioactive decay. A separate decay curve was constructed for each shipment of $\mathrm{K}^{\mathbf{2} / \mathbf{4}}$. Three separate dilutions of the isotope solution, each plated in triplicate, were assayed for radioactivity immediately before, at three intervals during, and immediately after the biological samples were assayed.

Triplicate potassium analyses were made from duplicate dilutions on aliquots of serum, lyzed erythrocytes, bladder urine, gastrointestinal contents, and excreted urine and stool with a lithium internal standard flame photometer. ${ }^{6}$ The sodium concentration was similarly determined on these samples. A correction was made for the contribution of sodium emissions to the potassium assay when necessary.

\section{B. Human subjects}

Thirteen human subjects were studied at the time of postmortem examination. The age, sex, weight and height of each subject was recorded. Patients with clinically demonstrable edema or organic gastrointestinal disease were eliminated from the study. The gross and microscopic postmortem findings were subsequently recorded. The techniques employed in collecting and analyzing the gastrointestinal contents are described in the first report in this series (4); the appendix to the first report summarizes the pertinent features of the case histories of these subjects.

Triplicate potassium analyses were made from dupli-

$\checkmark$ Radiobiological Apparatus Co., Berkeley, Calif.

- Baird Associates, Cambridge, Massachusetts. cate dilutions of the separate gastrointestinal contents using a lithium internal standard flame photometer.

\section{CALCULATIONS}

\section{A. Rabbits}

The total exchangeable potassium $\left(\mathrm{K}_{\odot}\right)$ was calculated from the dilution formula $(1,12)$ :

where:

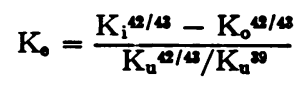

$\mathrm{K}_{\mathrm{i}^{12 / 4}}=$ Injected radiopotassium in counts per minute.

$\mathrm{K}_{0}{ }^{12 / 43}=$ Radiopotassium excreted in the urine (bladder plus cage urine) to time of equilibration bladder urine sample.

$\mathrm{K}_{\mathrm{u}}{ }^{2 / 48} / \mathrm{K}_{\mathrm{u}}{ }^{20}=$ Specific activity of bladder urine at equilibrium of distribution in counts per $\mathrm{mEq}$.

The degree of ionic exchange of intraluminal potassium with serum potassium was evaluated by relating gastrointestinal specific activities to the bladder urine specific activities.

where:

$$
\text { Specific activity ratio (S.A.R.) }=\frac{(\text { S.A. })_{t}}{(\text { S.A. })_{u}}
$$

(S.A.) $)_{t}=K_{t}^{10 / 43} / K_{t}^{\infty}=$ Tissue specific activity at equilibrium of distribution in counts per mEq.

(S.A.) $)=K_{u^{2}} 2 / 43 / K_{u^{20}}=$ Bladder urine specific activity at equilibrium of distribution in the counts per $\mathrm{mEq}$.

The value of this ratio is assumed to represent the fraction of gut potassium which was exchanged $(4,13)$.

To determine the validity of using bladder urine specific activity as a standard of reference for the specific activity of the gastrointestinal contents, simultaneous plasma specific activity and bladder urine specific activity were determined in 14 cases 21 to 24 hours after the injection of radiopotassium (Table I). The mean ratio of specific

TABLE I

Plasma versus bladder urine specific activity in the rabbit

\begin{tabular}{|c|c|c|c|}
\hline Rabbit & $\begin{array}{c}\text { Specific } \\
\text { activity } \\
\text { plasma } \\
\text { cts./mEq. } \times 10 \text { as }\end{array}$ & $\begin{array}{c}\text { Specific } \\
\text { activity } \\
\text { bladder } \\
\text { urine } \\
\text { cts./mEq. } \times 10^{a}\end{array}$ & $\frac{\begin{array}{c}\text { Specific activity } \\
\text { bladder urine }\end{array}}{\begin{array}{c}\text { Specific activity } \\
\text { plasma }\end{array}}$ \\
\hline $\begin{array}{r}1 \\
2 \\
3 \\
4 \\
5 \\
6 \\
7 \\
8 \\
9 \\
10 \\
11 \\
12 \\
13 \\
14\end{array}$ & $\begin{array}{c}119.3 \\
113.6 \\
63.73 \\
65.60 \\
81.12 \\
85.32 \\
77.89 \\
84.10 \\
94.67 \\
86.56 \\
99.13 \\
102.7 \\
90.96 \\
113.4\end{array}$ & $\begin{array}{c}116.3 \\
114.8 \\
73.20 \\
71.00 \\
94.53 \\
83.53 \\
74.51 \\
80.01 \\
102.8 \\
90.26 \\
96.67 \\
104.6 \\
109.3 \\
114.2 \\
\text { Mear } \\
\text { ard deviatio }\end{array}$ & $\begin{array}{l}0.97 \\
1.01 \\
1.14 \\
1.08 \\
1.16 \\
0.98 \\
0.95 \\
0.95 \\
1.09 \\
1.05 \\
0.97 \\
1.02 \\
1.20 \\
1.00 \\
1.04 \\
\pm 0.08\end{array}$ \\
\hline
\end{tabular}
21 to 24 hours after the injection of radiopotassium 


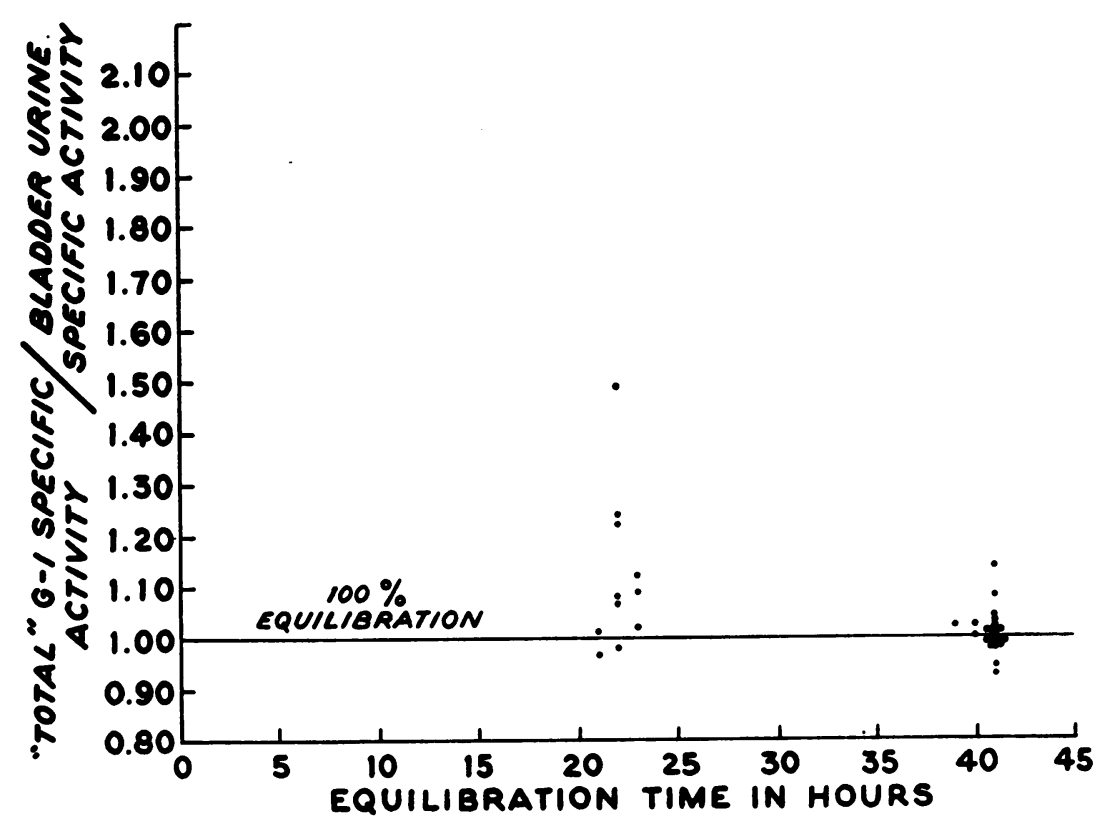

Fig. 1. The Equilibration of Gastrointestinal Potassium with Carcass Potassium, Using the Bladder Urine Specific Activity as Representative of Plasma Specific Activity, as a Function of the Time Allowed for Isotope Equilibration

activity bladder urine/specific activity plasma was $1.04 \pm$ 0.08. These results confirm those of Corsa and his colleagues (1). Because of errors which might be introduced by minimal hemolysis of blood in the preparation of plasma for assay and because of the relatively small amount of radioactivity in the plasma (due to the low potassium concentration), the specific activity of bladder urine was used as the more reliable standard of reference.

\section{B. Human subjects}

Samples from the human subjects were obtained and treated as described previously (4). The predicted $\mathrm{K}_{0}$ was estimated from published normal standards (14), taking into account the sex of the patient. Body weight was used as the reference unit. From studies on $\mathrm{K}_{0}$ in disease states, it is likely, however, that these estimates are generally too high up to a factor of 2 (14).

\section{RESULTS}

\section{A. Rabbits}

The effect of varying the time allowed for radiopotassium distribution on the ratio of total gastrointestinal to bladder urine specific activity is depicted in Figure 1.

A specific activity ratio of 1.00 is assumed to represent 100 per cent exchange. At 20 to 24 hours the specific activity ratio is quite variable,

TABLE II

The exchangeable potassium $\left(K_{\odot}\right)$ and gastrointestinal potassium content of male versus female rabbits

\begin{tabular}{|c|c|c|c|c|}
\hline & Male & Female & $\mathbf{t}$ & p \\
\hline \multirow{3}{*}{ 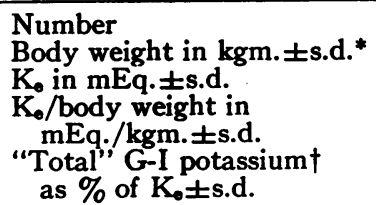 } & $\begin{array}{c}13 \\
2.05 \pm 0.14 \\
107.0 \pm 9.2\end{array}$ & $\begin{array}{c}13 \\
2.02 \pm 0.13 \\
100.8 \pm 10.1\end{array}$ & $\begin{array}{l}0.55 \\
1.90\end{array}$ & $\begin{array}{l}>0.5 \\
>0.1\end{array}$ \\
\hline & $52.2 \pm 4.3$ & $49.8 \pm 2.7$ & 1.70 & $>0.1$ \\
\hline & $5.9 \pm 1.8$ & $5.5 \pm 2.4$ & 0.422 & $>0.6$ \\
\hline
\end{tabular}

* s.d. $=$ standard deviation $=\sqrt{\frac{\Sigma(x-\bar{x})^{2}}{n}}$.

$\dagger$ "Total" G-I potassium refers to the intraluminal potassium content of the gastrointestinal tract from the cardia of the stomach to the mid-transverse colon. 
TABLE III

The exchangeable potassium $\left(K_{0}\right)$ content in the rabbit *

\begin{tabular}{lccccc}
\hline & $\begin{array}{c}\text { Body } \\
\text { weight } \\
k g m .\end{array}$ & $\begin{array}{c}\text { Serum } \\
\mathrm{K}\end{array}$ & \multicolumn{2}{c}{ Exchangeable K } \\
\cline { 5 - 6 } & 32 & 32 & & \multicolumn{2}{c}{$\begin{array}{c}m E q . / \\
k g m .\end{array}$} \\
\hline Number & 2.07 & 3.63 & 104.9 & 50.7 \\
$\begin{array}{l}\text { Mean } \\
\text { s.d. }\end{array}$ & \pm 0.16 & \pm 1.51 & \pm 9.7 & \pm 4.0 \\
$\begin{array}{l}\text { Coefficient of } \\
\text { variation }\end{array}$ & $7.5 \%$ & $41.6 \%$ & $9.2 \%$ & $8.0 \%$ \\
\hline
\end{tabular}

* Ko calculated 21 to 42 hours after the injection of radiopotassium.

often exceeding a value of 1.00 considerably. At 39 to 41 hours, however, the specific activity ratios cluster closely around 1.00, averaging 1.01 , with a range of 0.93 to 1.14 . It appears, therefore, that approximately 40 hours are required for uniform distribution of isotopic potassium between gut contents and the carcass.

Previous studies on normal human subjects have shown a sex difference in exchangeable potassium content; male subjects averaged $46.3 \mathrm{mEq}$. of potassium per $\mathrm{kgm}$. of body weight, while female subjects averaged $39.0 \mathrm{mEq}$. per $\mathrm{kgm}$. of body weight (14). To evaluate the possibility of similar sex differences in $\mathrm{K}_{e}$ of rabbits, pairs of animals, matched for weight, were studied; the data are presented in Table II.

The $\mathrm{K}_{\mathrm{e}}$ averaged $6.2 \mathrm{mEq}$. greater in male rabbits than in female rabbits. The differences, however, in $K_{e}, K_{e}$ per $\mathrm{kgm}$. of body weight, and "total" gastrointestinal potassium expressed as per cent of the $K_{e}$ were not statistically significant. Subsequent tabulations, therefore, were made without regard to the sex of the animal. In making this comparison, equilibration and fasting periods of 21 hours were employed for the most part. "Total" gastrointestinal potassium was distinctly lower in this group than in the animals subjected to 39 to 41-hour equilibration-fasting intervals ( $c f$. Table VI), in spite of the fact that the difference in the mean $K_{e}$ between these two groups of animals was not significant.

The exchangeable potassium content and the serum potassium concentrations are summarized in Table III. No significant difference in either $\mathrm{K}_{\mathrm{e}}$ or $\mathrm{K}_{\mathrm{e}}$ per $\mathrm{kgm}$. of body weight was found between the animals allowed 21 hours of equilibration of radiopotassium and those allowed 40 hours. In 13 rabbits, in which equilibration-fasting pe-
TABLE IV

The equilibration of $K^{12 / 4}$ with intraluminal gastrointestinal potassium in the rabbit*

\begin{tabular}{|c|c|c|c|c|c|}
\hline & \multirow[b]{2}{*}{ Number } & \multicolumn{4}{|c|}{ Specific activity ratio } \\
\hline & & Mean & s.d. & $t$ & $\mathbf{p}$ \\
\hline \multirow{3}{*}{$\begin{array}{l}\text { Stomach } \\
\text { Small intestine } \\
\text { Cecum and trans- } \\
\text { verse colon } \\
\text { "Total"gastro- } \\
\text { intestinal tract }\end{array}$} & $\begin{array}{l}23 \\
23\end{array}$ & $\begin{array}{l}1.00 \\
1.01\end{array}$ & $\begin{array}{l} \pm 0.043 \\
\pm 0.029\end{array}$ & $\begin{array}{c}0 \\
1.66\end{array}$ & $\begin{array}{r}1 \\
>0\end{array}$ \\
\hline & 23 & 1.01 & \pm 0.068 & 0.704 & $>0$ \\
\hline & 23 & 1.01 & \pm 0.042 & 1.14 & $>0.2$ \\
\hline
\end{tabular}

* $\mathrm{K}^{4 / 4} \mathrm{Cl}$ was injected 39 to 41 hours prior to sacrifice; the rabbits were fasted during this period.

$\dagger$ This ratio was obtained by dividing the specific activity of the gastrointestinal contents by the specific activity of the bladder urine.

riods of 21 to 24 hours were employed, the $\mathrm{K}_{\mathrm{e}}$ averaged $52.3 \pm 3.5 \mathrm{mEq}$. per $\mathrm{kgm}$. of body weight, while the mean $K_{e}$ in 23 rabbits after 39 to 42 hours of equilibration was $49.9 \pm 3.3 \mathrm{mEq}$. per $\mathrm{kgm}$. of body weight $(0.10>p>0.05)$. The average $K_{e}$ for the combined series was 104.9 mEq., or $50.7 \mathrm{mEq}$. per $\mathrm{kgm}$. of body weight, with a coefficient of variation of 8.0 per cent ( $c f$. Table III).

The question of exchangeability of gut potassium at various levels of the gastrointestinal tract was explored by measuring the intraluminal specific activity relative to bladder urine specific activity. These data are summarized in Table IV. All of the animals in this group were studied 39 to 41 hours after the injection of radiopotassium. At all levels of the gastrointestinal tract the mean specific activity ratio did not differ significantly from a value of 1.00 , being $1.00 \pm 0.043,1.01 \pm$ $0.029,1.01 \pm 0.068$, and $1.01 \pm 0.042$ for the stomach, small intestine, cecum and proximal transverse colon, and the "total" gastrointestinal

TABLE V

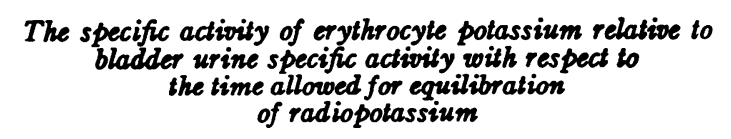

\begin{tabular}{cccc}
\hline \hline & & \multicolumn{2}{c}{ R.B.C. specific activity } \\
\cline { 3 - 4 } Number & $\begin{array}{c}\text { Equilibration } \\
\text { time } \\
\text { hours }\end{array}$ & \multicolumn{2}{c}{ Bladder urine specific activity } \\
\cline { 3 - 4 } & $21-23$ & Mean & Range \\
\hline 6 & $40-41$ & 0.49 & $0.46-0.54$ \\
6 & & 0.66 & $0.61-0.77$
\end{tabular}

* A specific activity ratio of less than 1.0 indicates incomplete exchange equilibrium. 
TABLE VI

The intraluminal gastrointestinal potassium content in the rabbit *

\begin{tabular}{|c|c|c|c|c|c|c|c|c|}
\hline & \multicolumn{2}{|c|}{ Stomach } & \multicolumn{2}{|c|}{ Small intestine } & \multicolumn{2}{|c|}{$\begin{array}{l}\text { Cecum and } \\
\text { transverse colon }\end{array}$} & \multicolumn{2}{|c|}{ “Total" G-I } \\
\hline & $m E q$. & $\%$ of $K_{\bullet}$ & $m E q$. & $\%$ of $K$ & $m E q$. & $\%$ of $K$ & $m E q$. & $\%$ of $K_{e}$ \\
\hline $\begin{array}{l}\text { Number } \\
\text { Mean } \\
\text { s.d. } \\
\text { Range }\end{array}$ & $\begin{array}{c}0.7 \\
\pm 0.3 \\
0.3-1.7\end{array}$ & $\begin{array}{r}0.7 \\
\pm 0.3 \\
0.3-1.6\end{array}$ & $\begin{array}{c}1.2 \\
\pm 0.4 \\
0.5-2.2\end{array}$ & $\begin{array}{c}1.2 \\
\pm 0.4 \\
0.5-2.3\end{array}$ & $\begin{array}{r}4.5 \\
+3.1 \\
1.7-12.8\end{array}$ & 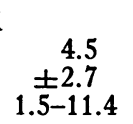 & $\begin{array}{r}7.1 \\
\pm 2.8 \\
2.9-15.6\end{array}$ & $\begin{array}{r}7.2 \\
\pm 2.2 \\
2.6-13.9\end{array}$ \\
\hline
\end{tabular}

* Period of fasting and equilibration of isotope was 39 to 41 hours.

$\dagger$ "Total" G-I potassium refers to the intraluminal potassium content of the gastrointestinal tract from the cardia of the stomach to the mid-transverse colon.

tract, respectively. It is apparent, therefore, that intraluminal potassium is completely exchangeable with the body potassium pool.

Radiopotassium dilution, even after 40 hours of equilibration, however, does not measure true total body potassium content. Erythrocyte potassium exchange is still incomplete 40 hours after injection. Red cell specific activity relative to bladder urine specific activity is 0.49 and 0.66 at 21 to 23 and 40 to 41 hours of equilibration, respectively ( $c f$. Table V). These findings agree closely with those of Corsa and his associates (1). Because of the short half-life of radiopotassium ( $\mathrm{K}^{42}=12.4$ hours, $\mathrm{K}^{43}=22.4$ hours), it is impractical to extend the period of tracer equilibration beyond 40 hours. This technique does measure approximately 95 per cent of body potassium, which is sufficient for the purposes of this study (1).

The amount and distribution of intraluminal potassium is summarized in Table VI. "Total" gastrointestinal potassium averaged $7.2 \pm 2.2$ per cent of the $\mathrm{K}_{\mathrm{e}}$. The cecum and proximal half of the transverse colon contained $4.5 \pm 2.7$ per

TABLE VII

The potassium content of the distal colon and the rate of stool potassium excretion in the rabbit

\begin{tabular}{|c|c|c|}
\hline & $\begin{array}{l}\text { Descending colon } \\
\text { and rectum }\end{array}$ & $\begin{array}{l}\text { Stool potassium } \\
\text { per } 24 \text { hours }\end{array}$ \\
\hline & $\begin{array}{lc}\text { Total } & \text { \% } \text { Total" of }^{\text {ot }} \\
\text { mEq. } & \text { potassium" }\end{array}$ & $\begin{array}{l}\text { Total "Total" } \\
\text { mEq. } \\
\text { potassium" }\end{array}$ \\
\hline $\begin{array}{l}\text { Number } \\
\text { Fasting period } \\
\text { Mean } \\
\text { Range }\end{array}$ & \begin{tabular}{cc}
\multicolumn{2}{c}{12} \\
$39-45$ hours \\
0.18 & 2.8 \\
$0.04-0.41$ & $0.6-5.0$
\end{tabular} & \begin{tabular}{cc}
\multicolumn{2}{c}{12} \\
$39-45$ hours \\
2.0 & 33 \\
$0-5.0$ & $0-87$
\end{tabular} \\
\hline
\end{tabular}

* "Total" G-I potassium refers to the intraluminal potassium content of the gastrointestinal tract from the cardia of the stomach to the mid-transverse colon. cent of the $\mathrm{K}_{\mathrm{e}}$, with lesser quantities in the small intestine and stomach, namely $1.2 \pm 0.4$ and $0.7 \pm$ 0.3 per cent, respectively. The potassium content of the proximal portion of the large bowel accounts for some 63 per cent of the total gastrointestinal potassium pool. In a similar series of rabbits the bulk of the gut sodium pool ( 72 per cent) was also found in the proximal segment of the large intestine (4). The range of values for gut potassium was quite large in spite of the rigid fasting conditions imposed. In this study as little as 2.6 per cent of the $K_{e}$ and as much as 13.9 per cent of the $\mathrm{K}_{\mathrm{e}}$ was contained in the gut.

The distal colon contains very little potassium, some 2.8 per cent of the "total" intraluminal potassium, at the end of a 39 to 41-hour fasting period. Fecal excretion of potassium during a 39 to 41-hour fasting period was moderate in absolute magnitude, $2 \mathrm{mEq}$. per day (range, 0 to 5 $\mathrm{mEq}$. per day), which is only 1.9 per cent of the mean $\mathrm{K}_{\mathrm{e}}$ (cf. Table VII). In relation to the pool size of gastrointestinal potassium, however, the fecal excretion rate is quite significant, amounting to 33 per cent of the "total" intraluminal potassium per day. In contrast, the rate of stool sodium excretion averages $0.4 \mathrm{mEq}$. per day, which is only 2.6 per cent of the "total" intraluminal sodium content (4).

Fecal excretion of potassium in fed rabbits is of considerable absolute magnitude. Three rabbits allowed pellets ${ }^{7}$ containing $53 \mathrm{mEq}$. of potassium per 100 grams, ad libitum, consumed $50 \mathrm{mEq}$. of potassium per day, or 50 per cent of their total exchangeable potassium content. In these animals fecal excretion rates varied from 4 to $13 \mathrm{mEq}$. of

? Pillsbury's Best Foods, 16 per cent protein rabbit pellets. 


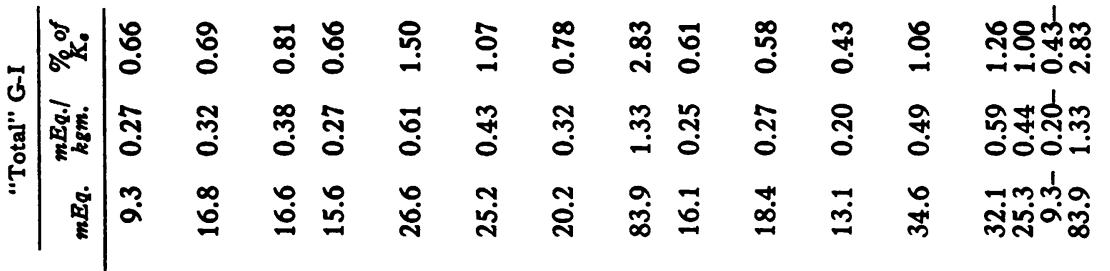

震|

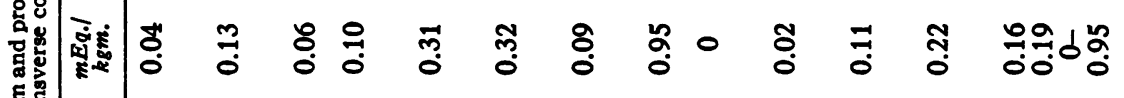

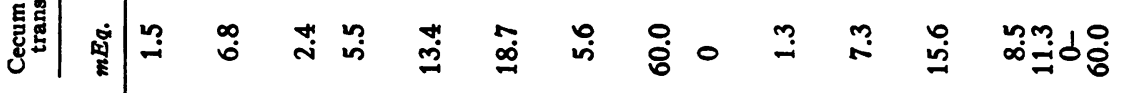

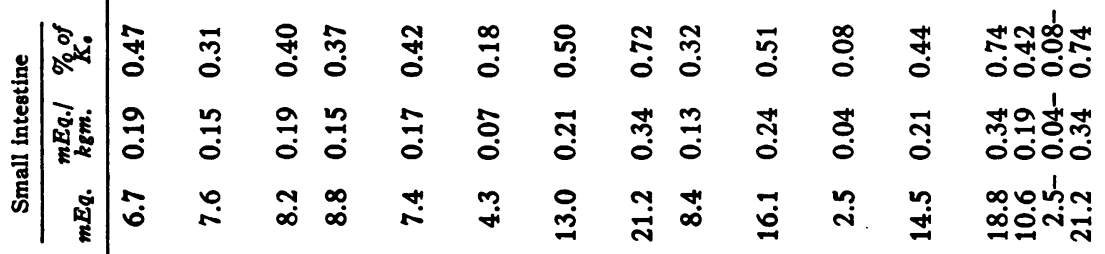

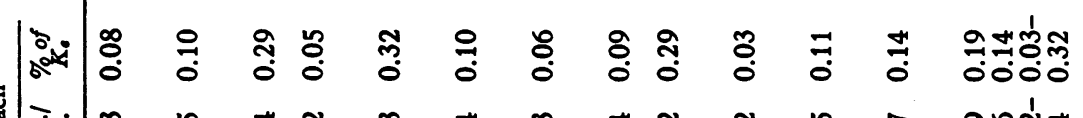
की

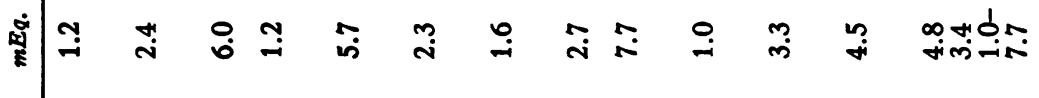

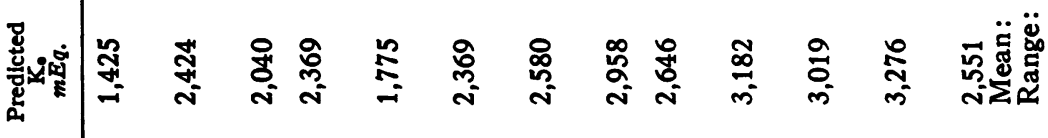

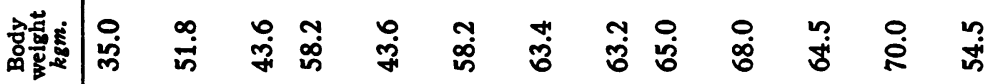

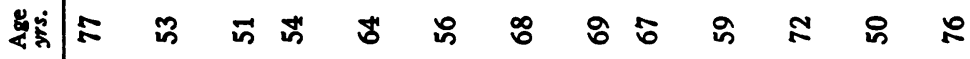

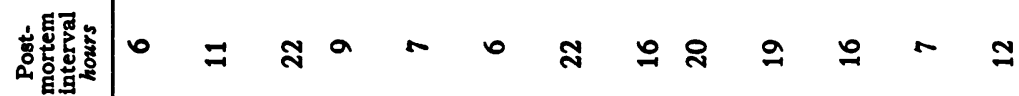

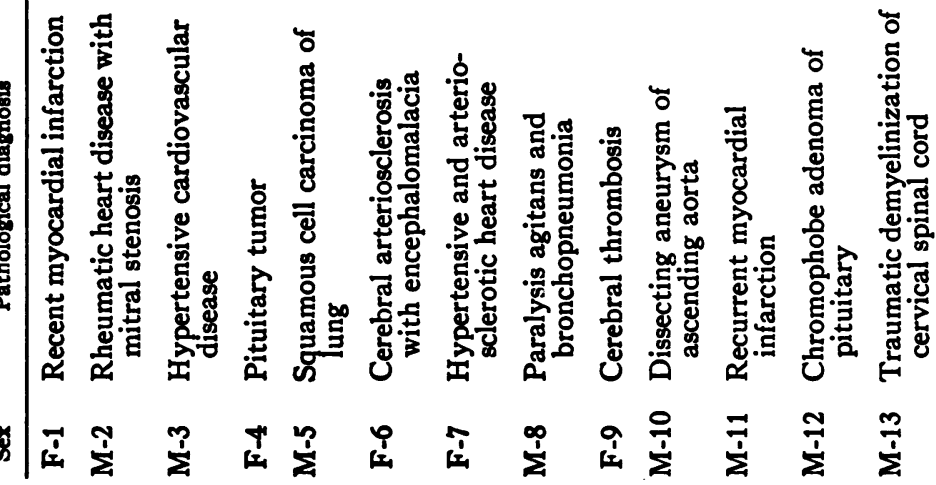


potassium per day, which is from 65 to 200 per cent of the "total" gut potassium content in the fasting state.

\section{B. Human subjects}

The results obtained on postmortem examination of human subjects are listed in Table VIII. The postmortem interval (the time between death and collection of gut contents) varied from 6 to 22 hours. No gross correlation between the quantity of gastrointestinal potassium and the postmortem interval is evident. Thirteen patients, 8 males and 5 females, whose ages at death ranged from 50 to 77 years, were studied. The clinical and pathological features of these cases are summarized in the appendix to the first report in this series (4). To express the intraluminal gastrointestinal potassium content in terms of the total labile pool of body potassium, a predicted $\mathrm{K}_{\mathrm{e}}$ was calculated for each case, taking into account the patient's sex and body weight, from previously published normal values (14). Mean "total" gastrointestinal potassium was $0.44 \mathrm{mEq}$. per $\mathrm{kgm}$. of body weight, or 1.0 per cent of the predicted $\mathrm{K}_{\mathrm{e}}$. The mean potassium content in the small intestine and proximal large intestine were equal, averaging $0.19 \mathrm{mEq}$. per $\mathrm{kgm}$. of body weight, or 0.42 per cent of the predicted $\mathrm{K}_{e}$; the stomach contents contained an average of 0.06 $\mathrm{mEq}$. per $\mathrm{kgm}$. of body weight, or 0.14 per cent of the predicted $\mathrm{K}_{\mathrm{e}}$. In man studied postmortem the distribution of gut potassium differs from the distribution of gut sodium, in that the cecum and proximal transverse colon contain about 43 per cent of gut potassium as against 22 per cent of gut sodium, while the stomach contains 14 per cent of gut potassium compared to 28 per cent of gut sodium (4).

\section{DISCUSSION}

The concentration of potassium in the gastrointestinal contents is almost always greater than that in plasma. In humans, the highest concentrations are found in saliva and small intestinal secretions, averaging $20 \mathrm{mEq}$. per liter and $11 \mathrm{mEq}$. per liter, respectively $(6-8)$. The lowest concentrations are found in the biliary and pancreatic se- cretions, where they approximate that in plasma. Nevertheless, intraluminal gastrointestinal potassium has been largely ignored in past considerations of the distribution of potassium in the body.

Gastrointestinal potassium is obviously extracellular and is freely exchangeable with plasma potassium. The high concentrations of potassium in most gastrointestinal secretions are probably indicative of an active transport mechanism from blood to gut (15). Intestinal transport of both sodium and potassium are affected by adrenal hormones. ACTH-treated nephrectomized rats, both fed and fasted, have an increased gut potassium content; conversely, adrenalectomy decreases the potassium content of the gut in rats (16). Adrenalectomy in dogs produces a sharp decrease in the rate of intestinal absorption of potassium, as well as of sodium and chloride, which is rectified by the administration of adrenal cortical hormones (17). It is likely, therefore, that both blood-to-gut and gut-to-blood transport of potassium involves active mechanisms dependent on energy-yielding metabolic processes.

The gastrointestinal specific activity ratios of $1.00,1.01,1.01$, and 1.01 for stomach, small intestine, proximal large bowel, and "total" gastrointestinal contents, respectively, demonstrate the complete exchangeability of gastrointestinal potassium ( $c f$. Table IV). Gastrointestinal potassium, is, therefore, an integral part of the total body pool of labile potassium, and is measured when the total exchangeable potassium is determined by the isotope dilution technique.

The amount of potassium contained in the gastrointestinal tract of the rabbit greatly exceeds that found in the remainder of the extracellular fluid. Kruhøffer (18) estimated the volume distribution of inulin in rabbits to be almost 20 per cent of the body weight. This volume would contain approximately $1.6 \mathrm{mEq}$. of potassium in a rabbit weighing $2 \mathrm{kgm}$. The "total" gastrointestinal potassium content of rabbits fasting 39 to 41 hours averaged $7.1 \mathrm{mEq}$., which is almost four and one-half times as much as in the interstitial-plasma compartment. Gut potassium could completely replace the interstitial-plasma potassium in rabbits in response to a metabolic need or contribute considerably to abnormal elevations in serum potassium concentrations in pathological states. Swan and Pitts (19) 
found that infusing acid loads in nephrectomized dogs resulted in a redistribution of body potassium and calculated a net increase of $31 \mathrm{mEq}$. of potassium in the interstitial-plasına fluid. It is conceivable that migration of potassium from gut to blood could account for a significant part of the increase in interstitial-plasma fluid potassium noted under these conditions.

The pool size of gut potassium may be considerably smaller in man than in rabbits. A 70-kgm. man has approximately $50 \mathrm{mEq}$. of potassium in the plasma-interstitial fluid compartment as estimated by thiosulfate dilution (20). In the postmortem studies on human subjects the intraluminal potassium content averaged $25 \mathrm{mEq}$., or approximately 50 per cent of the remainder of extracellular potassium (cf. Table VIII). These data obviously are not reliable, however, in making inferences relative to normal living subjects, since agonal influences may have induced marked shifts of potassium across the gut wall.

The mean $\mathrm{K}_{\mathbf{e}}$ of young adult rabbits was 50.7 $\mathrm{mEq}$. of body weight in this study (Table III). This value differs significantly from the mean of $56.1 \mathrm{mEq}$. of potassium per $\mathrm{kgm}$. of body weight in rabbits reported by Corsa and his colleagues (1). The discrepancy between these two values in all probability is due to the differences in weight and age of the animals comprising each series. In this study the mean weight was $2.07 \mathrm{kgm}$., while in the study of Corsa and his colleagues (1) the mean weight was $1.06 \mathrm{kgm}$. Forbes and Perley $(21,22)$ have shown similar differences in exchangeable sodium content (i.e., decreasing $\mathrm{Na}_{\mathrm{e}}$ per $\mathrm{kgm}$. of body weight) between children and adult humans. The animals in our series were 150 to 170 days old, while those reported by Corsa and his colleagues (1) were approximately 60 days old. Direct chemical analyses on sacrificed normal rabbits revealed a constant potassium content but an increase in body fat from approximately 4 per cent to 8 per cent of the body weight during this interval (23).

The total exchangeable potassium content is measurably lower in adult man than in the rabbit, averaging $43 \mathrm{mEq}$. per $\mathrm{kgm}$. of body weight ( 46.3 $\mathrm{mEq}$. per kgm. in males and $39.0 \mathrm{mEq}$. per kgm. in females) (14). This species difference may result, at least in part, from differences in intralu- minal gastrointestinal potassium content. The estimated gut potassium content is $0.44 \mathrm{mEq}$. per $\mathrm{kgm}$. of body weight in man at postmortem (Table VIII) and $3.5 \mathrm{mEq}$. per $\mathrm{kgm}$. of body weight in rabbits. In other words, about half the difference in $\mathrm{K}_{\mathrm{e}}$ may be accounted for on the basis of the greater content of intraluminal potassium in rabbits. Intraluminal potassium content in living man may differ considerably, however, from the quantity found at postmortem.

Gastrointestinal potassium amounts to 7.2 per cent of the $\mathrm{K}_{\mathrm{e}}$ in rabbits, with 63 per cent of the "total" intraluminal potassium, or 4.5 per cent of the $\mathrm{K}_{\boldsymbol{e}}$, in the cecum and proximal half of the transverse colon (Table VI). This is similar to the intraluminal distribution of sodium, since 72 per cent of gut sodium is contained in the proximal portion of the large bowel (4). The distal colon, in contrast, was found to contain only 0.2 per cent of the $\mathrm{K}_{\mathrm{e}}$, or 2.8 per cent of "total" gastrointestinal potassium. The rate of fecal excretion of potassium in the fasting rabbit averages 2 per cent of the $\mathrm{K}_{\mathrm{e}}$, or 33 per cent of "total" gastrointestinal potassium per day (Table VII). The rate of fecal excretion of potassium is about five times the rate of fecal sodium loss (4). The conservation of potassium by the proximal large bowel in the fasting rabbit is considerably less efficient, therefore, than the conservation of sodium.

In a group of 13 human subjects studied postmortem after suffering from a variety of illnesses, the "total" gastrointestinal tract contained an average of 1.0 per cent of the $\mathrm{K}_{\mathrm{e}}$, with 0.14 per cent, 0.42 per cent, and 0.43 per cent in the stomach, small intestine and proximal colon, respectively (Table VIII). The variation in potassium content of the gut is considerable, however, ranging from as little as $9 \mathrm{mEq}$. to as much as $84 \mathrm{mEq}$. in the cases studied. The distal colon may contain or transport quite large amounts of potassium as judged by analyses of enema returns. Dunning and Plum (24) found as much as $250 \mathrm{mEq}$. of potassium in a single tap water enema efflux in a patient with neurogenic bowel dysfunction.

Methods for in vivo estimation of intracellular potassium are necessarily indirect. Such estimates, based on multiple tracer techniques when inulin or sucrose is used to measure extracellular fluid content, will be in error in proportion to the 
amount of potassium in the transcellular fluid of the animal under study (4). Estimations of the concentration of potassium in intracellular water by these methods will be too low, since the ratio of potassium to water in transcellular fluid is small compared to the ratio in intracellular fluid $(2,5-8$, 25).

\section{SUM MARY}

Intraluminal gastrointestinal potassium content was measured in rabbits and in human subjects studied postmortem. In rabbits gut potassium was referred to the $K_{e}$, as determined with $\mathrm{K}^{\mathbf{4 2 / 4 8}}$. In human subjects gut potassium was referred to predicted $\mathrm{K}_{\mathrm{e}}$ values.

The total exchangeable potassium in rabbits averaged $50.7 \pm 4.0 \mathrm{mEq}$. per $\mathrm{kgm}$. of body weight. Of this, an average of $7.2 \pm 2.2$ per cent was contained in the "total" gastrointestinal tract, with $0.7 \pm 0.3$ per cent in the stomach, $1.2 \pm 0.4$ per cent in the small intestine, and $4.5 \pm 2.7$ per cent in the proximal half of the large intestine. Radiopotassium equilibrium was virtually complete at 40 hours after injection at all levels of the gastrointestinal tract, but not 24 hours after injection. No significant difference in $\mathrm{K}_{e}$ or the quantity of intraluminal gastrointestinal potassium was found between sexes.

Human subjects at postmortem examination had relatively small amounts of intraluminal gastrointestinal potassium; the mean values were 1.0 per cent of the predicted $\mathrm{K}_{\mathrm{e}}$ in the "total" gastrointestinal tract, with 0.14 per cent in the stomach, 0.42 per cent in the small bowel, and 0.43 per cent in the proximal half of the large bowel.

It is estimated that in the rabbit approximately 80 per cent of the total extracellular potassium is located in the gastrointestinal tract. In man, it is estimated that one-third of the total extracellular potassium is located in the lumen of the gastrointestinal tract postmortem. The relative quantity of intraluminal potassium in the normal living subject cannot be reliably inferred from these data, however.

\section{ACKNOWLEDGMENTS}

The authors are indebted to Dr. F. Gotch and to Miss M. R. Halligan for their technical assistance.

\section{REFERENCES}

1. Corsa, L., Jr., Olney, J. M., Jr., Steenburg, R. W., Ball, M. R., and Moore, F. D., The measurement of exchangeable potassium in man by isotope dilution. J. Clin. Invest., 1950, 29, 1280.

2. Hastings, A. B., The electrolytes of tissues and body fluids. Harvey Lectures, Ser. 36, 1940-1941, p. 91.

3. Deane, N., and Smith, H. W., The distribution of sodium and potassium in man. J. Clin. Invest., 1952, 31, 197.

4. Edelman, I. S., and Sweet, N. J., Gastrointestinal water and electrolytes. I. The equilibration of radiosodium in gastrointestinal contents and the proportion of exchangeable sodium $\left(\mathrm{Na}_{e}\right)$ in the gastrointestinal tract. J. Clin. Invest., 1956, 35, 502.

5. Cizek, L. J., Total water content of laboratory animals with special reference to volume of fluid within the lumen of the gastrointestinal tract. Am. J. Physiol., 1954, 179, 104.

6. Lockwood, J. S., and Randall, H. T., The place of electrolyte studies in surgical patients. Bull. New York Acad. Med., 1949, 25, 228.

7. Smith, F. H., Potassium deficiency in gastrointestinal diseases. Gastroenterology, 1950, 16, 73.

8. Bernstein, R. E., The potassium, sodium, and calcium content of gastric juice. I. Normal values. J. Lab. \& Clin. Med., 1952, 40, 707.

9. Burnett, C. H., Burrows, B. A., and Commons, R. R., Studies of alkalosis. I. Renal function during and following alkalosis resulting from pyloric obstruction. J. Clin. Invest., 1950, 29, 169.

10. Tarail, R., and Elkinton, J. R., Potassium deficiency and the role of the kidney in its production. $\mathrm{J}$. Clin. Invest., 1949, 28, 99.

11. Eisenman, A. J., Smith, P. K., Winkler, A. W., and Elkinton, J. R., The transfer of ions across the stomach wall, studied by means of radioactive isotopes, in Proc. Am. Soc. of Biol. Chemists. J. Biol. Chem., 1941, 140, XXXV.

12. Moore, F. D., Determination of total body water and solids with isotopes. Science, 1946, 104, 157.

13. Edelman, I. S., James, A. H., Baden, H., and Moore, F. D., Electrolyte composition of bone and the penetration of radiosodium and deuterium oxide into dog and human bone. J. Clin. Invest., 1954, 33, 122.

14. Moore, F. D., Edelman, I. S., Olney, J. M., James, A. H., Brooks, L., and Wilson, G. M., Body sodium and potassium. III. Inter-related trends in alimentary, renal and cardiovascular disease; lack of correlation between body stores and plasma concentration. Metabolism, 1954, 3, 334.

15. Visscher, M. B., The absorption and excretion of potassium in the intestine. J. Lancet, 1953, 1, 173.

16. Woodbury, D. M., Extrarenal effects of desoxycorticosterone, adrenocortical extract and adrenocorticotrophic hormone on plasma and tissue electrolytes in fed and fasted rats. Am. J. Physiol., 1953, 174, 1. 
17. Dennis, C., and Wood, E. H., Intestinal absorption in the adrenalectomized dog. Am. J. Physiol., 1940, 129, 182.

18. Kruhøffer, P., Inulin as an indicator for the extracellular space. Acta physiol. Scandinav., 1946, 11, 16.

19. Swan, R. C., and Pitts, R. F., Neutralization of infused acid by nephrectomized dogs. J. Clin. Invest., 1955, 34, 205.

20. Cardozo, R. H., and Edelman, I. S., The volume of distribution of sodium thiosulfate as a measure of the extracellular fluid space. J. Clin. Invest., 1952, $31,280$.

21. Forbes, G. B., and Perley, A., Estimation of total body sodium by isotopic dilution. I. Studies on young adults. J. Clin. Invest., 1951, 30, 558.
22. Forbes, G. B., and Perley, A., Estimation of total body sodium by isotopic dilution. II. Studies on infants and children: An example of a constant differential growth ratio. J. Clin. Invest., 1951, 30, 566.

23. Spray, C. M., and Widdowson, E. M., The effect of growth and development on the composition of mammals. Brit. J. Nutrition, 1950, 4, 332.

24. Dunning, M., and Plum, F., Potassium washout by enemas. Am. J. Med., 1955, 19, 288.

25. Gotch, F., Nadell, J., and Edelman, I. S., Gastrointestinal water and electrolytes. IV. The equilibration of deuterium oxide in gastrointestinal contents and the proportion of total body water in the gastrointestinal tract. In preparation. 